Nguyen, T. Q., and Waikar, S. S. (2018). "A relook at plan reliability measurements in lean construction and new metrics from digitized practical implementation." In: Proc. $26^{\text {th }}$ Annual Conference of the International. Group for Lean Construction (IGLC), González, V.A. (ed.), Chennai, India, pp. 1037-1046. DOI: doi.org/10.24928/2018/0216. Available at: www.iglc.net

\title{
A RELOOK AT PLAN RELIABILITY MEASUREMENTS IN LEAN CONSTRUCTION AND NEW METRICS FROM DIGITIZED PRACTICAL IMPLEMENTATION
}

\author{
Thi Qui Nguyen ${ }^{1}$ and Sharath Sridhar Waikar ${ }^{2}$
}

\begin{abstract}
Lean construction is increasingly being adopted in many countries as a means to improve construction project performance and productivity. Measuring the various improvements towards achieving the outcomes of reliability, preparedness, commitment and collaborative culture is crucial for a sustained successful practical implementation of Lean. Among various Lean techniques and tools, the Last Planner System (LPS) method has been widely used in construction projects for its simplicity and applicability to the construction environment. With LPS, the plan reliability is measured by Percent Plan Complete (PPC). The PPC as a single metric has been found to be insufficient in providing actionable information in understanding the root cause of challenges faced in different projects nor in improving the reliability nor in getting valid commitment of key project parties. It is also ineffective to symbolize as the metric to represent the preparedness, capacity or performance of the different sub-contractors. This paper aims to provide an in-depth review of PPC and other reliability measurements and their advantages and shortfalls for practical implementation. It reviews the symbolic representation of PPC to improvement through the application of Lean methods in construction from a planning and management perspective. From these analysis, this paper introduces a framework for practical implementation of Lean construction. It also proposes new metrics to supplement PPC to accurately represent plan reliability for better understanding of the root causes. The proposed indices are validated using data obtained from the digital application of Lean construction processes using Lean PlanDo. Lean PlanDo is digital tool embedded with Lean principles for construction planning and management based on LPS with a key emphasis on Value Stream Mapping (VSM) and constraint management. The proposed indices will provide the project teams with practical measurements and to build upon their understanding of Lean, measure the effectiveness of planning and the application of Lean methods in the project.
\end{abstract}

1 R\&D Manager, Lean Station Ptd. Ltd., 73 JTC LauncPad Ayer Rajah Crescent, \#02-27, Singapore, S139952, +6587483827, qui@ leanstation.com

2 CEO, Co-founder, Lean Station Ptd. Ltd., 73 JTC LauncPad Ayer Rajah Crescent, \#02-27, Singapore, S139952,+6597508940, sharath@leanstation.com 


\section{KEYWORDS}

Lean construction, percent plan complete (PPC), construction productivity, digital construction, data analysis, reliable planning, valid commitment

\section{INTRODUCTION}

Construction productivity has been flat over several decades while other labour-intensive industries are experiencing improved productivity. Poor planning, lack of commitment and blame-game culture have led to weaker control over construction processes. These have compounded the problem of project delays, wasted time, defects and reworks.

Lean construction has been promoted as an effective approach for improving productivity in construction (Aziz, et al., 2013) through better project planning and control. It is the application of lean thinking into construction projects, and essentially focuses on maximizing the performance and value for the customer and minimizing waste. In general, lean construction make projects easier to manage, safer, completed sooner, and cost less and of better quality.

Reliable planning is vital for achieving a successful project performance (Laufer, et al., 1993). Master and phase scheduling defines the scope of work and provides the longterm vision of the entire project from which project managers can make suitable strategy decisions. Lookahead and weekly planning on the other hand provide detailed action plans to the site team for commitment and execution. At any time of the project, construction plans at both macro (master- and phase planning) and micro (lookahead- and weekly planning) should be dynamically integrated with the current project conditions so that they be executed on site. While there exist different metrics to measure the plan reliability at different level, they are found missing this dynamic nature, and thus fail to capture the true reliability.

Last Planner System (LPS) (Ballard, 1994) is one of the most common Lean methods being adopted in the construction industry. This approach emphasizes on micro planning and aims to improve the workflow reliability of the construction plan and reduce the negative impacts caused by variability. Although the key input to this planning system is the master schedule, its dynamicity is not integrated. This missing element would lead the team to outdated and or unachievable project targets, and the related reliability KPIs may not truly describe the plan reliability picture. In addition, the main reliability measurement of the LPS is the Percent Plan Complete (PPC) which focuses only on very micro planning level and overlooks the importance of macro planning.

This paper is to provide a review the existing metrics of planning reliability and how they are interpreted in practical applications. It also presents the execution framework for practical adoption of Lean concepts and the LPS which is currently been used in the Singapore construction industry. This framework is implemented in Lean PlanDo - a digital tool for Lean construction project planning and management. New plan reliability indices are also proposed and subsequently illustrated through a simulated case study. 


\section{LAST PLANNER SYSTEM (LPS) AND ITS RELATED PLAN RELIABLITY MEASUREMENT}

\section{OVERVIEW OF LPS}

The Last Planner System is one of the most common Lean techniques which has been demonstrated to be a very useful approach for the planning and control of construction processes (Aziz, et al., 2013). It comprises of two main processes: Lookahead planning elaborating project milestones into action plans, and weekly work planning describing the weekly execution plan. These processes provide a better control on both construction workflow and production unit.

The sequence of last planner process (illustrated in Figure 1) consists four main steps: (1) master and phase scheduling defining the scope of work and milestones - what SHOULD be done to achieve the project targets; (2) lookahead planning elaborating project targets into work sequences (tasks) and constraints that need to be cleared before execution - what CAN be done; (3) Weekly work plan determine what will be executed by the team - WILL do; and (4) DID - what was achieved.

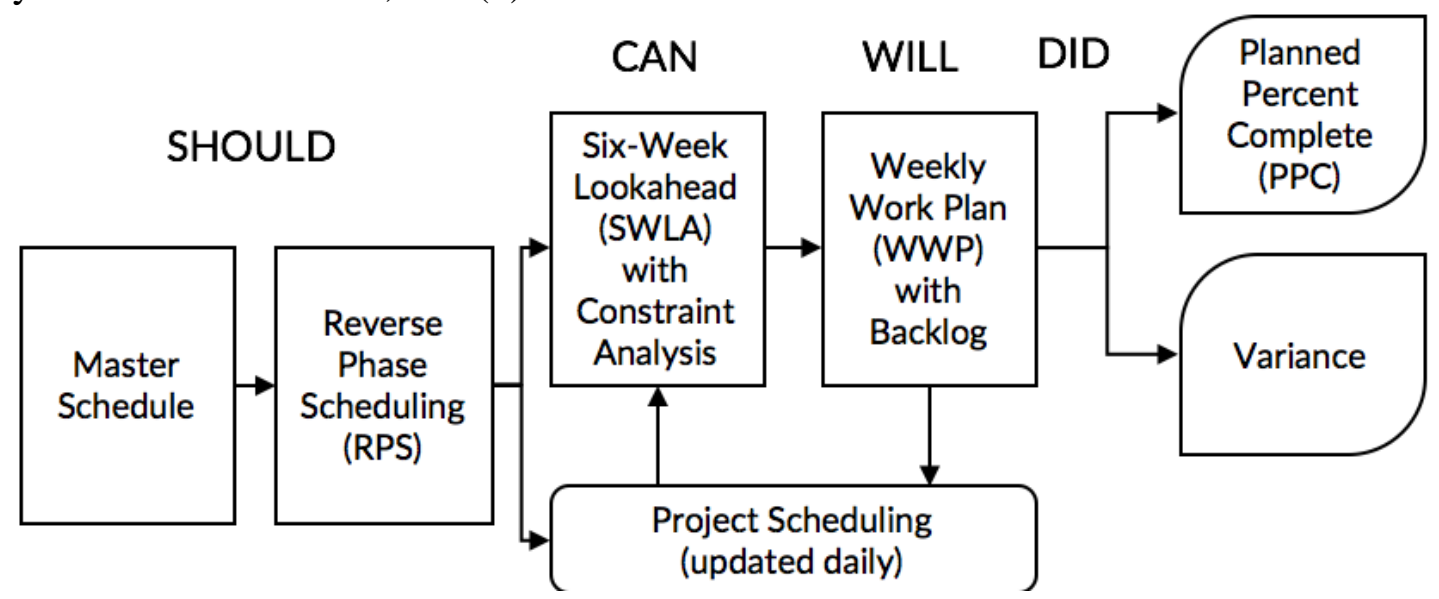

Figure 1: Planning sequence of the last planner process (Aziz, et al., 2013).

One of the fundamentals of the LPS is reliable promises or commitments through reducing workflow uncertainty and variation so that only tasks that are well defined, sounded with right sizing will be allocated for execution. This shielding process also helps improve the reliability of planning and boost up productivity (Hamzeh, et al., 2015).

\section{PLAN RELIABILITY MEASUREMENTS}

Different metrics have been developed to represent the reliability of planning at different phases and are summarized in

Table 1 from macro to micro planning levels.

It can be found from the summary that the PPC, TA and TMR indices are mainly focus on short-term planning reliability and yet lack the description for long-term 
planning targets in the master and phase schedules. In addition, since the calculation of PPC are mainly based on the number of tasks completed versus committed and disregards the task sizes, it does not provide sufficient information for the site team on sizing their capacity to fit the targeted progress which has been defined in the long-term plans. It is also widely recommended by LCI that higher PPC is preferable and projects should target a PPC range of $75 \%$ to $90 \%$ for good performance (Emdanat, et al., 2016). However, data obtained from practical implementation show that aiming only increasing PPC through reducing the number of commitments will not improve project performance, yet the team capacity should be increased according the long-term plan requirements. In other words, focusing only on short-term reliability and especially PPC may mislead the project team from long-term milestones.

CL and PRCO metrics are solutions to link short- and long-term planning targets. However, the dynamic nature of long-term plans is not considered, which may lead to outdated targets to be considered in the calculations. In addition, the metrics are built at activity level and thus missing a link to enhance the execution.

Table 1: Summary of plan reliability metrics

\begin{tabular}{|c|c|c|c|}
\hline $\begin{array}{l}\text { Plan } \\
\text { reliability }\end{array}$ & $\begin{array}{l}\text { Metric and } \\
\text { Author }\end{array}$ & Description & Calculation \\
\hline $\begin{array}{l}\text { Master/Pha } \\
\text { se plan }\end{array}$ & $\begin{array}{l}\text { Commitment } \\
\text { Level (Emdanat, } \\
\text { et al., 2016) }\end{array}$ & $\begin{array}{l}\text { Percent of the total } \\
\text { committed required } \\
\text { activities of the total } \\
\text { required activities (when } \\
\text { its Late Start date falls } \\
\text { within the work planning } \\
\text { window time) on a work } \\
\text { plan when a new work } \\
\text { plan is created. }\end{array}$ & $\begin{array}{l}\text { CL = Required WILL } \\
\text { / SHOULD }\end{array}$ \\
\hline \multirow[t]{2}{*}{$\begin{array}{l}\text { Lookahead } \\
\text { plan }\end{array}$} & $\begin{array}{l}\text { Tasks } \\
\text { Anticipated } \\
\text { (Hamzeh, et al., } \\
\text { 2012) }\end{array}$ & $\begin{array}{l}\text { Percent of tasks on a work } \\
\text { plan that were anticipated } \\
\text { in the previous plan } 2 \\
\text { weeks earlier }\end{array}$ & $\mathrm{TA}=\mathrm{WILL} / \mathrm{CAN}$ \\
\hline & $\begin{array}{l}\text { Tasks Made } \\
\text { Ready (Hamzeh, } \\
\text { et al., 2012) }\end{array}$ & $\begin{array}{l}\text { Percent of completed tasks } \\
\text { in a given work plan that } \\
\text { were anticipated in a prior } \\
\text { work plan }\end{array}$ & TMR = DID / CAN \\
\hline $\begin{array}{l}\text { Weekly } \\
\text { work plan }\end{array}$ & $\begin{array}{l}\text { Percent Plan } \\
\text { Complete } \\
\text { (Ballard, 2000) }\end{array}$ & $\begin{array}{l}\text { Percent of completed } \\
\text { commitments to the total } \\
\text { commitments }\end{array}$ & $\mathrm{PPC}=\mathrm{DID} / \mathrm{WILL}$ \\
\hline
\end{tabular}




$\begin{array}{lll}\begin{array}{l}\text { Percent Required } \\ \text { Completed or }\end{array} & \begin{array}{l}\text { Percent of the required } \\ \text { activities that are } \\ \text { Cngoing }\end{array} & \begin{array}{l}\text { PRCO = (Required to } \\ \text { be Done + Ongoing }\end{array} \\ \begin{array}{l}\text { (Emdanat, et al., } \\ \text { their promised completion } \\ \text { dates }\end{array} & \text { Will } \\ \end{array}$

\section{FRAMEWORK FOR LEAN CONSTRUCTION PROJECT PLANNING AND MANAGEMENT}

This section presents an execution framework for project planning and management using Lean construction techniques called Lean PlanDo (LPD). The kernel value of LPD centres at its ability to marry strategic long-term planning (CPM) with Lean construction techniques (LPS and Value Stream Mapping) and constraint-based planning. The planning and controlling cycle is described in Figure 2.

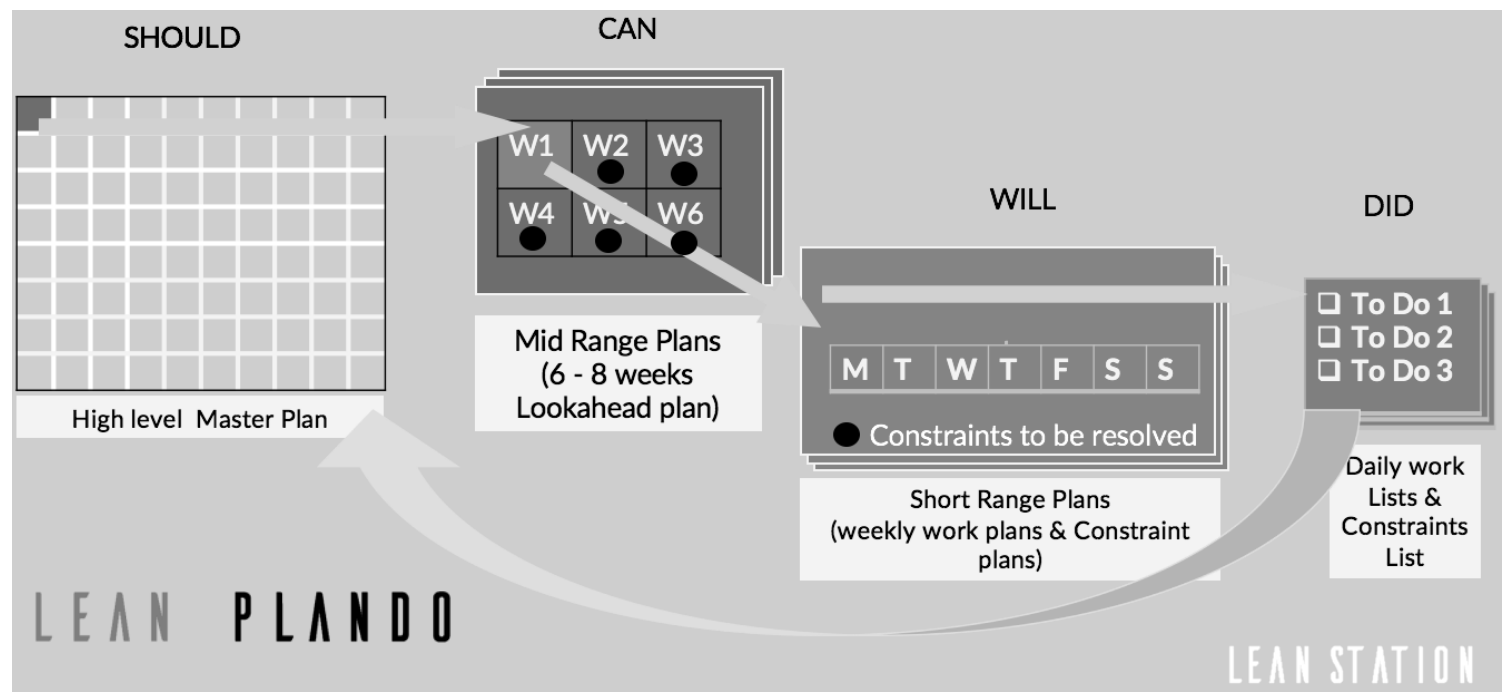

Figure 2: Lean construction project planning and management framework (LPD)

Inheriting LPS features, the planning workflow of LPD also starts from a high-level master plan indicating project scopes and milestones. Lookahead plans are sized at 6 or 8 weeks and created in a weekly basis, which allow the project team plan out the required construction plans with proper task sizes and sequences for value-added works. Essential non-value-added works are considered as constraints which hinder the construction works are also identified and assigned for accountable parties. Subsequently, the weekly work plans provide detailed information on the works (tasks) to be executed and constraints need to be handled to make future works ready. The weekly plans are then broken down into daily To-do list for monitoring and updating in a daily basis. The daily progress and status for both construction works and constraints are integrated back into the lookahead and master plans, providing accurate real-time information about the project. The weekon-week planning and controlling cycle is presented in Figure 3. 


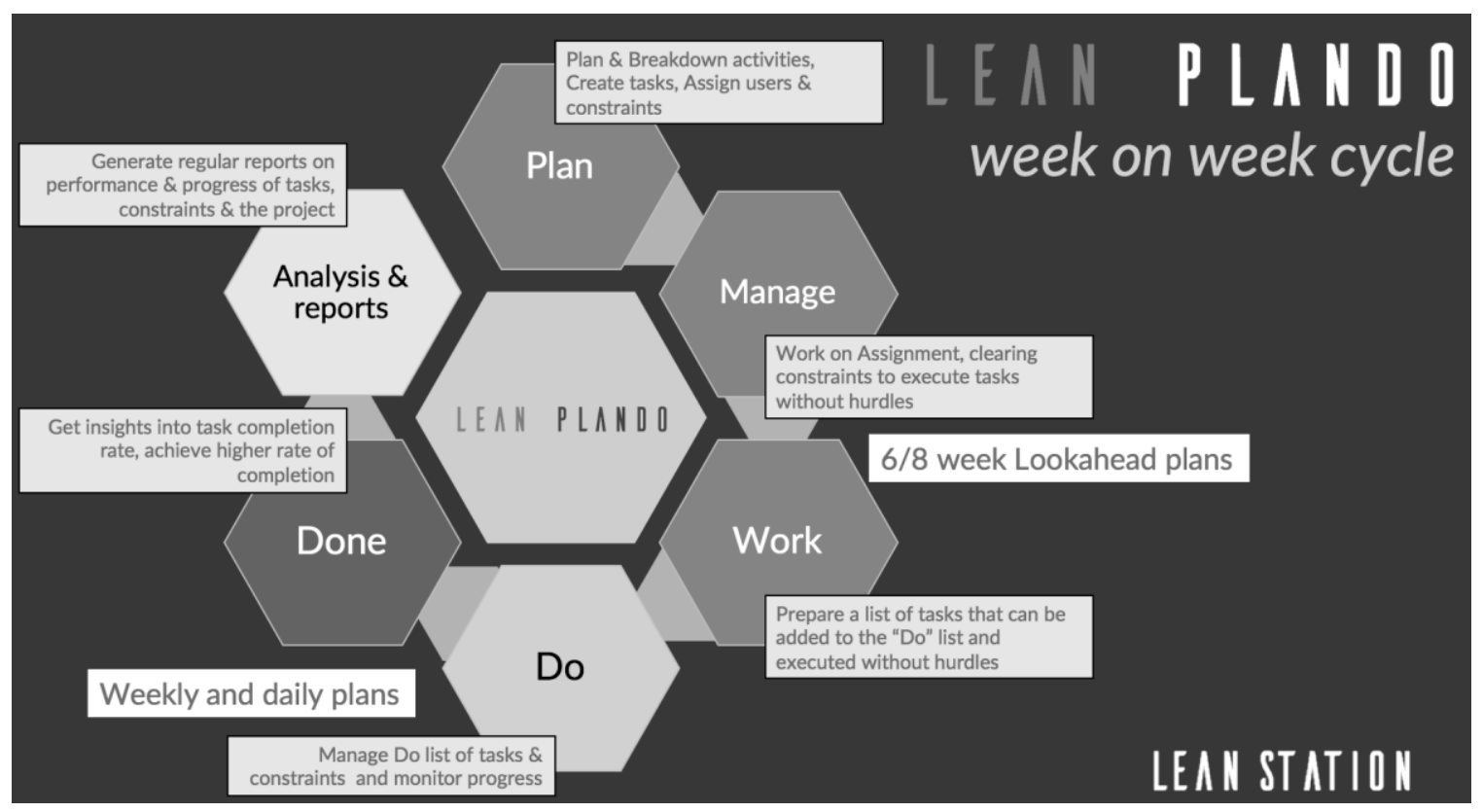

Figure 3: Week-on-week planning and controlling cycle

With this bi-directional planning and controlling framework, the master plan is always updated with latest project data and thus provides better guidance for the project team. Long-term plans now can be dynamically revised and adjusted to the site and project situations. Essentially, it provides a direct link throughout SHOULD - CAN - WILL DID plans in one single system, and allows for improved plan reliability metrics.

LPD has been widely adopted in Singapore as one of the leading Lean construction tools in the industry. The typical organization of a LPD team comprises of three main teams:

(1) Planning team: in-charge of lookahead planning for both construction works and milestones for constraint management. It involves experienced team members with both planning and practical execution knowledge.

(2) Coordination team: in-charge of constraint management. They are responsible for clearing constraints and make everything ready so that the related construction works can be started as plan.

(3) Site team: in charge of site work and project monitoring. This team with the cooperation of supervisors and the execution team (subcontractors) is to make sure the construction to be conducted and update site progress daily. 


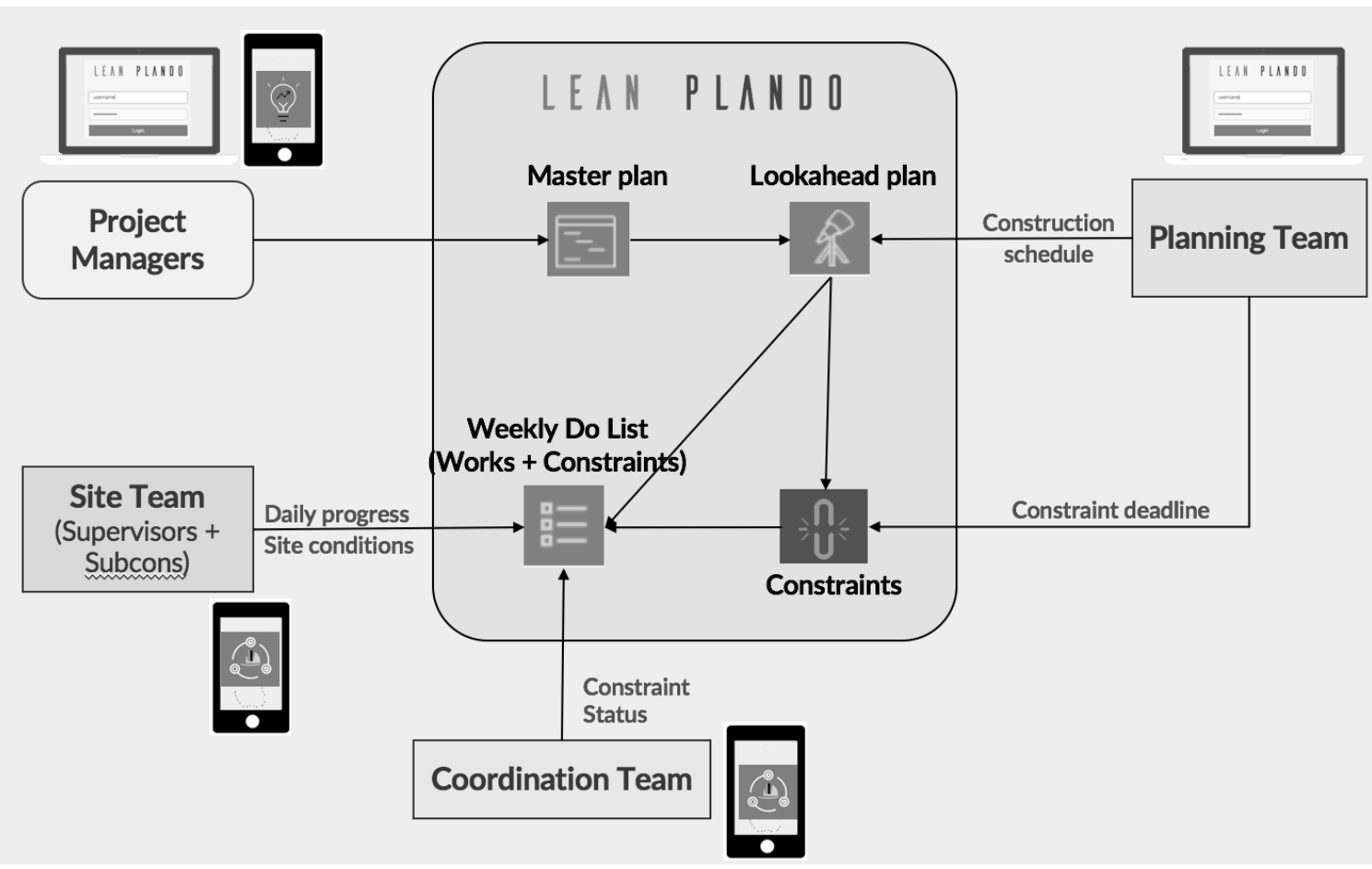

Figure 4: Information flow and team involvement in LPD

\section{PLAN RELIABILITY METRICS}

The above framework provides the consistent link between long-term and short-term plans. This integration also allows for improvements of the existing plan reliability metrics. The reliability of any plan is determined by various factors including the ability/knowledge to identify and resolve crucial constraints, the readiness of the site and site team, and capacity and dynamic performance of the site team to keep the commitment. Moreover, one of the key differences between construction and production systems is that the amount of work need to be done is not fixed but changes over weeks according to the target milestones (which can be seen through the progress $\mathrm{S}$ curve). Thus, a weekly performance index should incorporate required capacity or task size information. A closer look on all these factors is necessary to better illustrate plan reliability. In this context, for any given plan (in a weekly basis), the following reliability metrics should be visualized:

(1) Constraint resolution level (CAN vs SHOULD): The percent of task that can be done (constraint-free) in compared with tasks that should be done to achieve the milestones required by the master plan. The difference between CAN and SHOULD demonstrate the ability of identifying and resolving the recognized constraints.

(2) Site readiness level (WILL vs CAN): The percent of tasks that the team will take up against the total number of tasks that can be done. This metric represents the readiness level of the project team including site condition and site team. 
(3) Commitment level or PPC (DID vs WILL): The percent of tasks that are done against the committed tasks. The difference between DID and WILL can express the lack of capacity from the execution team or unanticipated constraints that hinder the site works.

(4) Capacity level or normalized PPC (normalized DID vs normalized WILL): The percent of task units that are done against the committed task units. This difference describes the quantum of capacity shortage to execute the committed amount.

(5) Overall plan reliability (DID vs SHOULD): The overall reliability level of the dynamic plan strategy is presented as the percent of tasks that are done and tasks that should be done. The difference between DID and SHOULD presents the gap between what is achieved and what is planned, and thus the reliability of the plan. This gap can be linked to all the delay reasons that affected in the past weeks for better understanding of the root causes of plan variations, from which improvements can be implemented in the future planning cycles.

The interpretation of the proposed metrics is presented in the illustrative example presented in the next section.

\section{ILLUSTRATIVE EXAMPLE}

A simplified drain construction project is used to illustrate the application of the proposed framework and reliability metrics. The master program of this project is created using Microsoft project (Figure 5) and imported into Lean PlanDo. The project is run under simulation mode for illustration purpose. Case study of actual project data will be presented in the presentation once this is approved by the data owners.

Each activity in the master plan is then elaborated into a series of tasks. Crucial constraints are added identified and added to the system for management. Under the simulation mode, this project is completed after 6 weeks, and delayed by 2 days. Weekly data of the proposed metrics are presented in Figure 6.

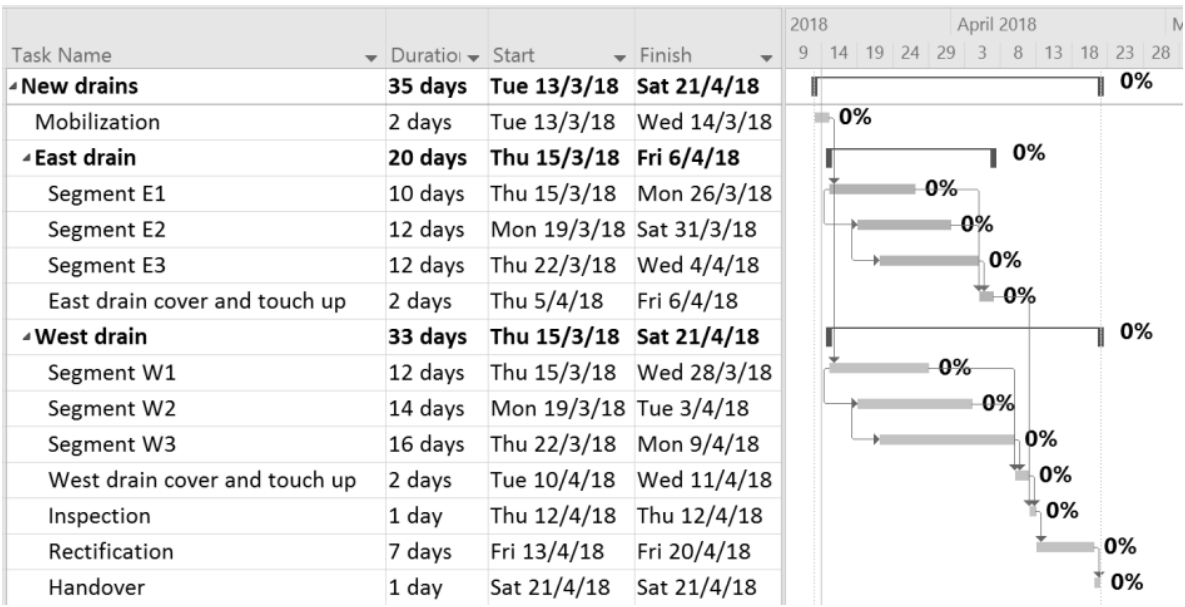

Figure 5: Master plan of drain construction project 


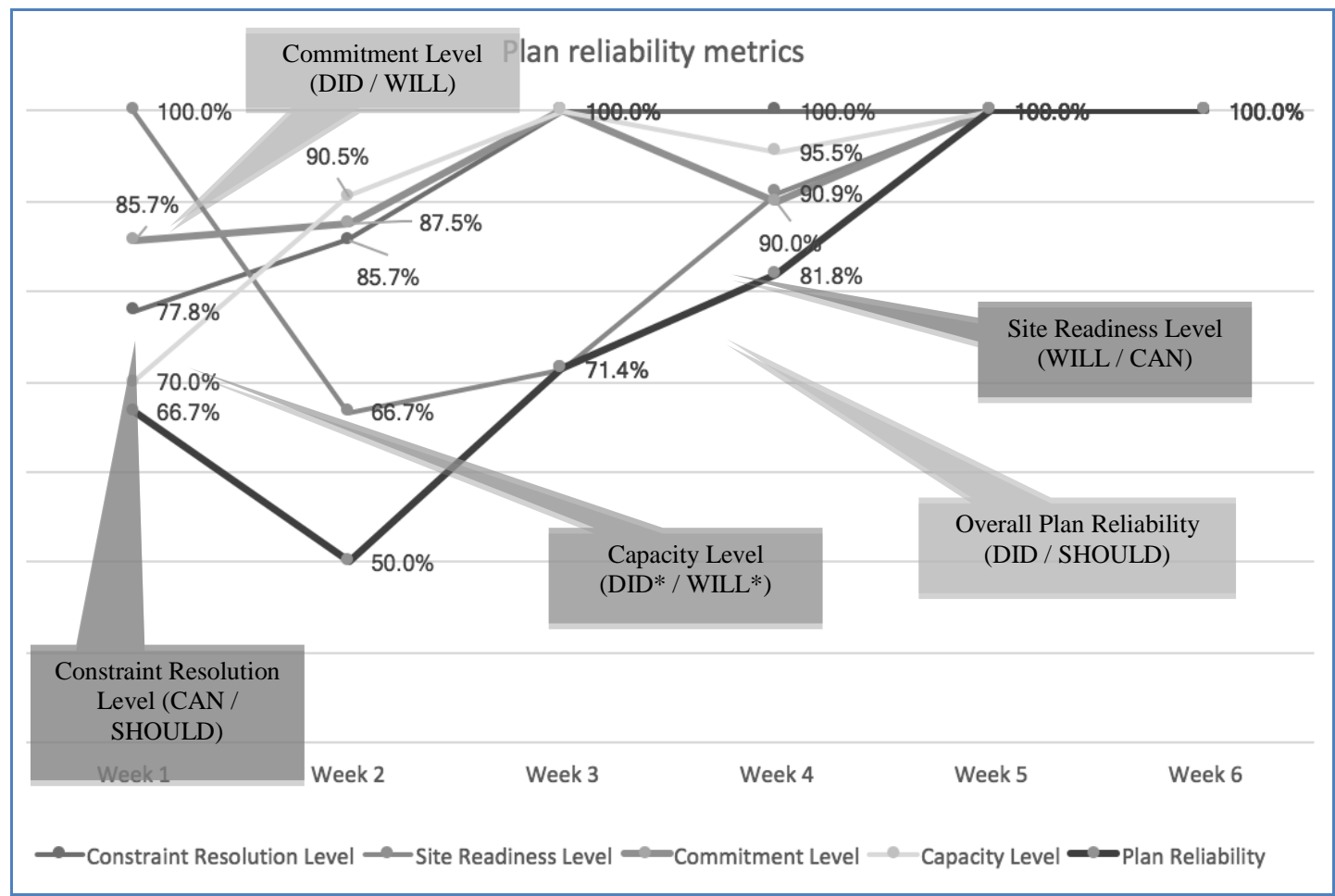

Figure 6: Plan reliability metrics

- In week 1 , the site is $100 \%$ ready to take up all do-able work, but the committed level (PPC) is achieved at $85.7 \%$. The capacity level is at $77.8 \%$ indicating manpower shortage issue. The overall plan reliability is at $66.7 \%$ as there is a big gap between SHOULD and DID.

- In week 2, as the team aims to enhance PPC, they committed only what they think they can do and increases their capacity, and thus the Site readiness level is very low $(66.7 \%)$ and thus the overall plan reliability is very low at $50 \%$.

- In week 3, the team continue to commit work with their capacity, keeping the site readiness level is also low at $71.4 \%$, but they manage to achieve $100 \%$ PPC. However, the plan reliability is still at $71.4 \%$.

- In the remaining weeks, as all constraints are resolved properly in advance (constraint resolution level is $100 \%$ ), and the team has met the required capacity, PPC is increased and thus plan reliability also increases.

\section{CONCLUSION}

Reliable planning is crucial for good project performance. Planning should be dynamically done at both long-term and short-term levels with real-time consideration of site situation. The existing plan reliability metrics are found to have two drawbacks: focusing only on short-term plan, and/or basing on a static master plan. They therefore 
may not present the in-depth understanding of the Lean process and root causes of delays. This paper presents a framework for Lean construction project planning and management which incorporates CPM, LPS and VSM methods. Lean PlanDo enables the direct link between long-term and short-term plans and due its nature of a cloud-based platform, it allows for real-time collaboration and actionable decision making.

The binding between long- and short-term plans into one single data set allows for the development of new reliable metrics: Constraint Resolution Level (CAN vs SHOULD), Site Readiness Level (WILL vs CAN), Commitment Level (or PPC) (DID vs WILL) and Plan Reliability (DID vs SHOULD). The Capacity Level (normalized PPC based on task size) is also introduced to represent the capacity of the team. The new metrics will effectively describe the effectiveness of Lean process and the overall plan reliability in a dynamic nature. They provide better understanding of the root causes of delays and assist teams with continual learning and improvement in people intensive construction projects.

\section{REFERENCES}

Aziz, R. F. and Hafez, S. M. (2013). "Applying lean thinking in construction and performance improvement” Alexandria Engineering Joural, Vol. 52 (4), 679-695.

Ballard, G. (1994). “The Last Planner", Report, Northern California Construction Institute

Ballard G. (2000). "The Last Planner System of Production Control”, PhD. Dissertation, The University of Birmingham, UK.

Emdanat, S. and Azambuja, M. (2016)."Aligning near and long term planning for LPS implemenetations: a review of existing and new metrics", Lean construction journal, pp. 90-101.

Hamzeh F., Ballazard, G. and Tommelein, I. (2012). "Rethinking lookahead planning to optimize construction workflow" Lean Construction Journal, pp. 15-34.

Laufer A., Shapira A., Cohenca, D. and Howell, G. (1993). "Prebid and preconstruction planning process", Journal of Construction Engineering Management. ASCE, Vol. 119. - pp. 426-444.

Hamzeh F., Farook R.,Saab, I., Tommelein, I. D., and Ballard, G.(2105). "Understanding the role of "task anticipated" in lookahead planning through simulation". Automation in construction. Part A : Vol. 49. - pp. 18-26. 